\title{
5'PPP-RNA induced RIG-I activation inhibits drug-resistant avian H5N1 as well as 1918 and 2009 pandemic influenza virus replication
}

\author{
Priya Ranjan', Lakshmi Jayashankar1, Varough Deyde', Hui Zeng1', William G Davis', Melissa B Pearce1, \\ John B Bowzard', Mary A Hoelscher', Victoria Jeisy-Scott' ', Mayim E Wiens'1, Shivaprakash Gangappa', \\ Larisa Gubareva1', Adolfo García-Sastre2, Jacqueline M Katz1', Terrence M Tumpey¹, Takashi Fujita*3 and \\ Suryaprakash Sambhara*1
}

\begin{abstract}
Background: Emergence of drug-resistant strains of influenza viruses, including avian $\mathrm{H} 5 \mathrm{~N} 1$ with pandemic potential, 1918 and 2009 A/H1N1 pandemic viruses to currently used antiviral agents, neuraminidase inhibitors and M2 lon channel blockers, underscores the importance of developing novel antiviral strategies. Activation of innate immune pathogen sensor Retinoic Acid Inducible Gene-I (RIG-I) has recently been shown to induce antiviral state.

Results: In the present investigation, using real time RT-PCR, immunofluorescence, immunoblot, and plaque assay we show that 5'PPP-containing single stranded RNA (5'PPP-RNA), a ligand for the intracytoplasmic RNA sensor, RIG-I can be used as a prophylactic agent against known drug-resistant avian $\mathrm{H} 5 \mathrm{~N} 1$ and pandemic influenza viruses. 5'PPP-RNA treatment of human lung epithelial cells inhibited replication of drug-resistant avian H5N1 as well as 1918 and 2009 pandemic influenza viruses in a RIG-I and type 1 interferon dependant manner. Additionally, 5'PPP-RNA treatment also inhibited 2009 H1N1 viral replication in vivo in mice.
\end{abstract}

Conclusions: Our findings suggest that 5'PPP-RNA mediated activation of RIG-I can suppress replication of influenza viruses irrespective of their genetic make-up, pathogenicity, and drug-sensitivity status.

\section{Background}

Annual influenza epidemics caused by influenza A and B viruses result in three to five million cases of severe illness with about 250,000 to 500,000 deaths globally every year. In the United States, complications from influenza infections result in approximately 250,000 hospitalizations and 36,000 deaths in an average year, with majority of the fatalities occurring among the elderly population [1]. Influenza A viruses are further sub typed based on hemagglutinin (HA) and neuraminidase (NA) proteins present on the virion envelope and there are $16 \mathrm{HA}$ and 9 NA types known among influenza A viruses [2,3]. Frequent minor genetic changes, known as antigenic drift

\footnotetext{
*Correspondence: tfujita@virus.kyoto-u.ac.jp, ssambhara@cdc.gov

1 Influenza Division, NCIRD, Centers for Disease Control and Prevention, 1600 Clifton Road, Atlanta, GA 30333, USA

3 Laboratory of Molecular Genetics, Institute for Virus Research, Kyoto University, Kyoto, Japan

Full list of author information is available at the end of the article
}

and the emergence of influenza A viruses with novel NA and/or HA subtypes, known as antigenic shift result in epidemics and pandemics respectively. In the $20^{\text {th }}$ century, only viruses of the $\mathrm{H} 1, \mathrm{H} 2$ or $\mathrm{H} 3$ and $\mathrm{N} 1$ or $\mathrm{N} 2$ subtypes have caused sustained epidemics in humans. However, other subtypes namely H7, H9, and H5 which primarily cause infections and death among avian species have crossed the species barrier and caused mild to severe or fatal disease in humans [4]. Since 2003, highly pathogenic avian influenza (HPAI) H5N1 viruses have expanded their geographical distribution and are currently endemic in domestic poultry and wild birds in approximately 60 countries on three continents [5]. As of May 61, 2010, 498 human cases in 15 countries with a $60 \%$ mortality rate have been reported [6]. Consequently, these viruses have the potential to cause a pandemic, if they acquire the ability for sustained transmission among humans $[7,8]$. In fact we are in the midst of a pandemic as 
a result of sustained human-to-human transmission by a novel $\mathrm{H} 1 \mathrm{~N} 1$ virus containing the gene segments from avian, human, and swine influenza viruses to which people lack immunity [9-11].

Vaccination is the primary strategy for reducing the morbidity and mortality associated with human influenza [12-15]. However, the population at risk such as elderly, pediatric, transplant recipients, and others who are immunocompromised with either primary or secondary immunodeficiency disorders remain vulnerable despite vaccination as in case of avian influenza viral infection and children, adolescents, pregnant women, and those with underlying medical conditions as in case of 2009 H1N1 pandemic influenza virus infection [16]. Therefore, the use of antiviral drugs is a crucial public health countermeasure for preventing and treating influenza, particularly in circumstances of increased incidence influenza infections when there is a vaccine mismatch or shortage, when vaccine usage is limited or non-existent, or when there is no effective vaccine available globally in the market as in the case of H5N1 virus infections. Currently, two classes of antiviral drugs are available to treat influenza infections: the M2 ion-channel blockers amantadine and rimantadine and the NA inhibitors oseltamivir and zanamivir [17-20]. However, the emergence of human seasonal, highly virulent $\mathrm{H} 5 \mathrm{~N} 1$ influenza viruses as well as 2009 H1N1 pandemic influenza viruses that are resistant to one or both the classes of drugs underscores the need for development of new generation drugs as well as other novel preventive and therapeutic strategies [13,21-28].

The immune system has evolved to recognize and eliminate pathogens. A number of pathogen recognition receptor (PRRs) families are involved in pathogen sensing and can be present in the host as soluble molecules in tissue fluids and serum or as molecules on cell membranes, localized in various cellular compartments, or in the cytosol [29-31]. Recognition of pathogen-associated molecular patterns (PAMPs) by PRRs results in rapid induction of innate immune responses that include production of antiviral cytokines such as the type I interferons (IFN-I) as well as proinflammatory cytokines responsible for impairment of viral replication and induction of adaptive immune responses [32]. The presence of viral RNA or DNA in cytosol is detected by retinoic acid inducible gene-I (RIG-I) and melanoma differentiationassociated gene 5 (MDA-5), DNA-dependent activator of IFN-regulator factors (DAI) or absent in melanoma 2 (AIM2) [33-36]. Several human viruses, including hepatitis $\mathrm{C}(\mathrm{HCV})$, vaccinia, Ebola, and influenza have evolved strategies to target and inhibit distinct steps in the early signaling events that lead to IFN-I induction, indicating the importance of IFN-I in the host's antiviral response [37-40]. In case of influenza viruses, we and others have shown that nonstructural protein 1 (NS1) inhibits the function of the RIG-I [41-44]. RIG-I is critical for the induction of an antiviral innate immune response against influenza virus and its $\mathrm{C}$-terminal helicase domain contains the characteristic amino acid signature motif of many RNA binding proteins [45]. The interaction of Cterminal domain with viral RNA either short double stranded RNA or 5'PPP-ssRNA with a panhandle structure facilitates its interaction with IPS- 1 (interferon- $\beta$ promoter stimulator 1 ) via its $\mathrm{N}$-terminal CARD (caspase-recruitment domain) [42,46-48]. Recent reports suggest various ligands for RIG-I including ssRNA and dsRNA that may require specific sequences or may not require a triphosphate on their 5'-termini [42,46-53]. Despite the various reports that describe ligands and mechanisms of RIG-I mediated antiviral response there is no report that suggests that RIG-I activation can inhibit replication of influenza viruses irrespective of their genetic makeup, pathogenecity and drug-resistant status. In the present study, we investigated whether the evolutionarily conserved antiviral strategies such as the stimulation of RIG-I with 5'PPP-RNA inhibit the replication of these influenza viruses.

\section{Results}

5'PPP-RNA inhibits the replication of 1918 pandemic virus as well as both wild-type and drug-resistant H5N1

The 1918 pandemic resulted in 20-50 million deaths worldwide. To test if the activation of RIG-I with 5'PPPRNA could suppress the replication of the reconstructed 1918 virus, we treated A549 cells with 5'PPP-RNA or CIAP-RNA for $24 \mathrm{hr}$, and then infected them with 1918 virus at an MOI of 0.01. Supernatants were collected 24 hr post-infection and assayed for viral titer. Figure $1 \mathrm{~A}(\mathrm{i})$ indicates that 5'PPP-RNA was able to inhibit 1918 virus replication by $\sim 99 \%$ compared with control or CIAPRNA treated cells. Similar inhibitory effect was observed in experiments where 0.1 MOI was used for infection (data not shown).

Next we evaluated the prophylactic antiviral potential of 5'PPP-RNA against avian influenza H5N1 viruses with pandemic potential. A549 cells were transfected with 5'PPP-RNA or CIAP-RNA for 0,24 or $48 \mathrm{hr}$, and infected with A/Vietnam/1203, an H5N1virus. Viral titers were determined $24 \mathrm{hr}$ post-infection. As shown in Figure $1 \mathrm{~A}(\mathrm{ii})$, A549 cells treated with 5'PPP-RNA showed antiviral effect after $24 \mathrm{hr}$ of transfection. This effect was not seen in control or in CIAP-RNA transfected A549 cells. This inhibitory effect persisted even after $72 \mathrm{hr}$ (data not shown) suggesting a sustained antiviral effect of 5'PPPRNA.

Stockpiling of the antiviral drug, oseltamivir is one strategy for pandemic preparedness, but the emergence of oseltamivir-resistant $\mathrm{H} 5 \mathrm{~N} 1$ viruses would seriously impede these efforts. Hence, we also tested the ability of 

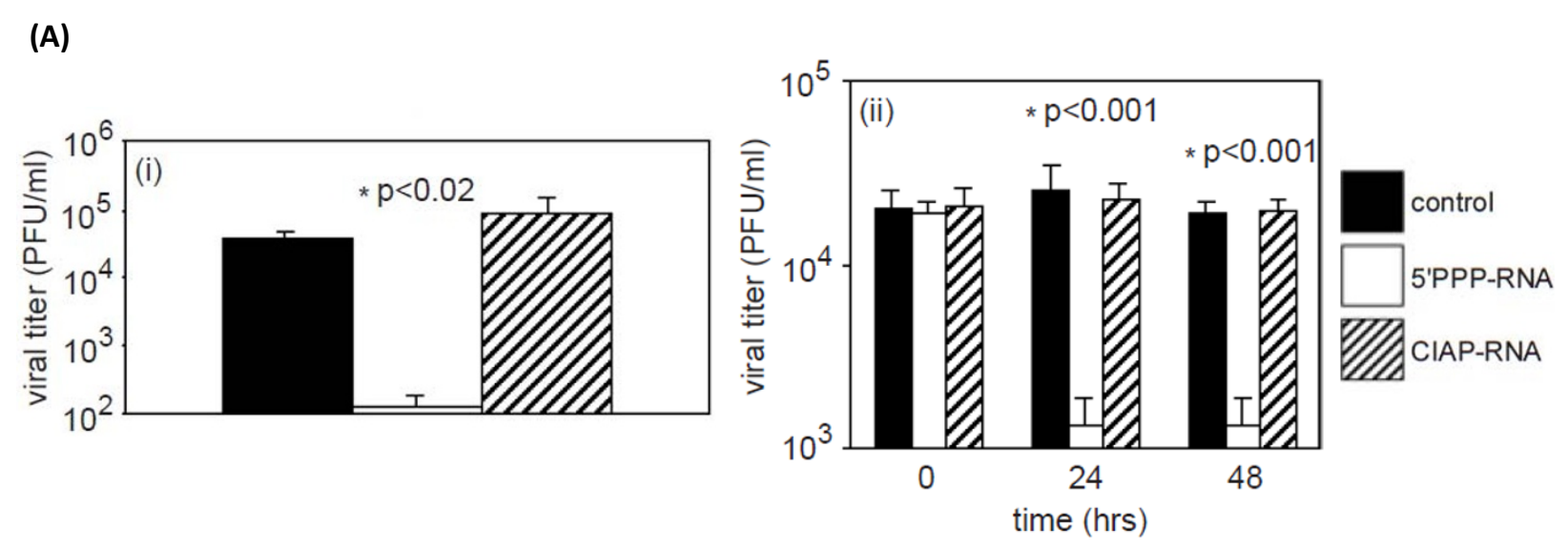

(B)

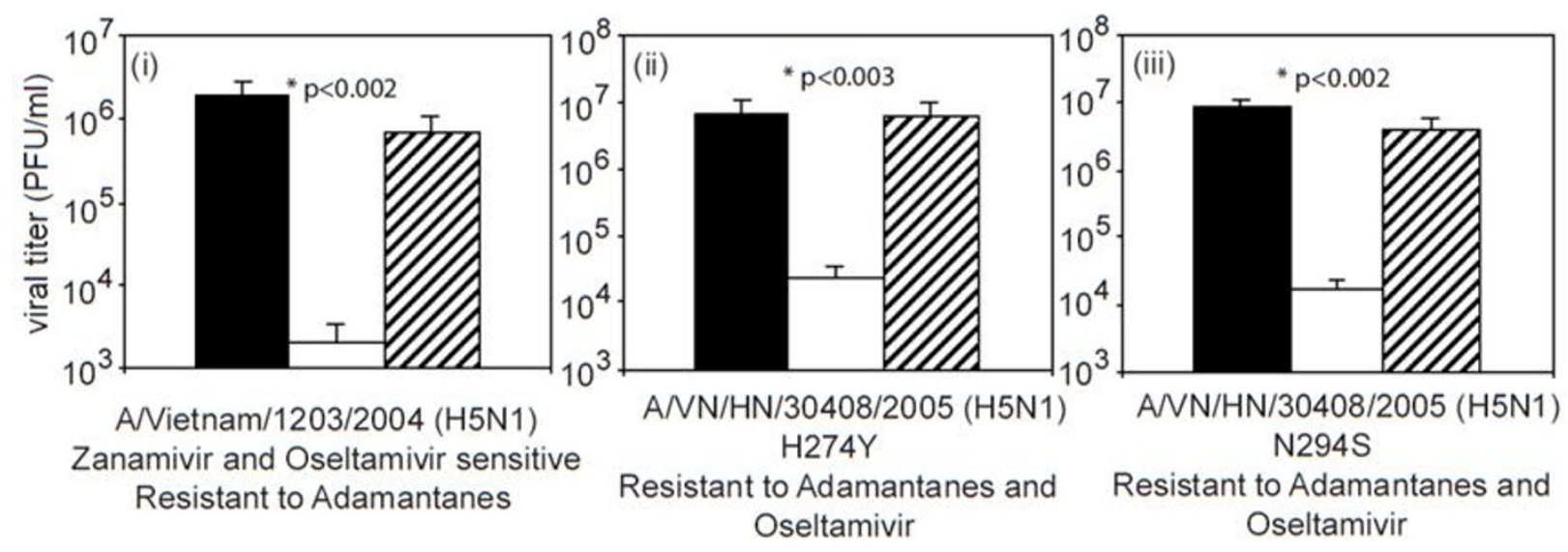

Figure 1 5'PPP-RNA suprresses the replication 1918 virus as well as wild-type and drug-resistant H5N1 viruses. (A) A549 (1 $\left.\times 10^{6} \mathrm{cells} / \mathrm{well}\right)$ in a 6-well tissue culture plate were mock-transfected (control) or transfected with $2 \mu \mathrm{g}$ of 5'PPP-RNA or CIAP-RNA using lipofectamine 2000 and $24 \mathrm{hr}$ later were infected with (i) 1918 pandemic virus (0.01 MOI). (ii), Transfected A549 cells were also infected with wild-type H5N1 (0.1 MOI) following 0, 24 and 48 hr of transfection. B. Mock, 5'PPP-RNA or CIAP-RNA transfected A549 cells were infected with drug-resistant H5N1 viruses A/VN/1203/2004 (i), ANN/30408/2004 H274Y(ii) and ANN/30408/2004 N294S (iii) $24 \mathrm{hr}$ post transfection. Supernatants collected after $24 \mathrm{hr}$ of infection were assayed for viral titers and results shown are mean \pm SD of three independent experiments and are expressed as viral titer (pfu/ml).

5'PPP-RNA to inhibit the replication of drug-resistant A/ Vietnam/1203/2004 viruses that include zanamivir- and oseltamivir-sensitive and adamantanes-resistant and adamantanes- and oseltamivir-resistant virus variants, $\mathrm{A} /$ $\mathrm{VN} / 30408 / 2005$ (H274Y) and A/VN/HN/30408/2005 (N294S). As shown in Figure 1B(i-iii), 5'PPP-RNA transfection in A549 cells significantly reduced the replication of all the three drug-resistant H5N1 viruses. A549 cells treated with CIAP-RNA did not have any impact on viral replication and viral titers were comparable to control. We also used NHBE cells in our studies with H5N1 infection, and similar antiviral effects of 5'PPP-RNA were observed (data not shown). Seasonal drug-resistant $\mathrm{H} 1 \mathrm{~N} 1$ and H3N2 and their wild-type counter parts were chosen to measure the efficacy of 5'PPP-RNA treatment on viral replication. Influenza viruses of different $\mathrm{HA}$ and NA and members of the same subtype have different rep- lication efficiencies. The replication efficiencies of these viruses were well characterized in MDCK cells. As expected, 5'PPP-RNA treatment of A549 cells inhibited the replication of wild-type and drug-resistant human seasonal $\mathrm{H} 1 \mathrm{~N} 1, \mathrm{H} 3 \mathrm{~N} 2$ and $\mathrm{B}$ viruses (Additional file 1, Figure S1). In all cases, activation of RIG-I pathway by 5'PPP-RNA transfection inhibited viral replication by 1.5 to 3 logs. Furthermore, we investigated if the viruses that grew in the presence of 5'PPP-RNA treatment were escape mutants that developed resistance to type I interferon. As shown in Additional file 2, Figure S2, the viruses that grew in the presence of 5'PPP-RNA are still susceptible to 5'PPP-RNA treatment when tested subsequently.

\section{5'PPP-RNA inhibits 2009 pandemic H1N1 viruses both in} vitro and in vivo

Global spread of novel 2009 A/H1N1 influenza viruses containing a constellation of genes from avian, human, 
and swine in relatively short period of time is causing severe disease and fatal outcomes in high-risk populations. It was clear that vaccine was not available and in sufficient quantities for use in the first wave of a pandemic leading to the reliance on the prophylactic and therapeutic use of effective antiviral drugs. However, emergence of oseltamivir-resistant novel 2009 A/H1N1 virus strains underscores the fragility of the public health strategy to control pandemic [27]. Hence, we tested the ability of 5'PPP-RNA to inhibit novel 2009 A/H1N1 virus. As shown in Figure 2A, 5'PPP-RNA transfected A549 cells significantly inhibited A/California/08/09 replication. Control or CIAP-RNA did not show this suppression effect. To investigate if in vivo administration of 5'PPP-RNA will reduce viral titers, we delivered 5'PPPRNA or PBS formulated in in vivojet-PEI daily for four days and infected mice on day 1 with A/Mexico/4482/09. Daily administration of 5'PPP-RNA alone had no side effects on body weight gain and activity (data not shown).

(A)

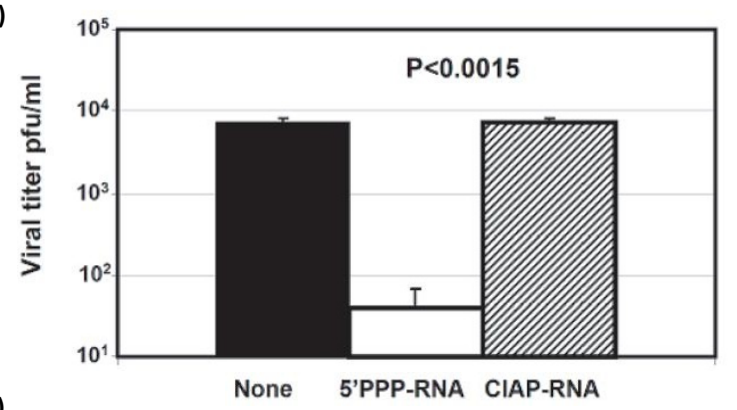

(B)

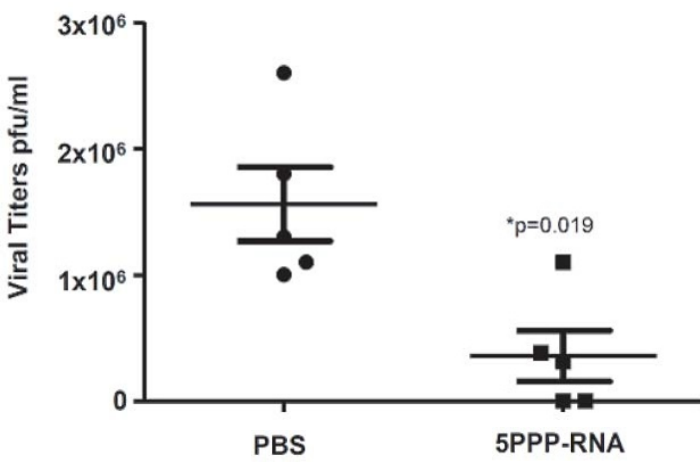

Figure 2 5'PPP-RNA inhibits replication of $\mathbf{2 0 0 9}$ pandemic influenza virus. (A). A459 cells $\left(1 \times 10^{6}\right.$ cells/well) in a 6-well tissue culture plate were mock-transfected or transfected with $2 \mu \mathrm{g}$ of 5 'PPP-RNA or CIAP-RNA for $24 \mathrm{hr}$ and then infected with A/California/08/09 at an $\mathrm{MOl}$ of 1.0. Supernatants collected $24 \mathrm{hr}$ post-infection were assayed for viral titers as indicated in material and methods. Results shown are mean \pm SD from three independent experiments and are expressed as viral titer (pfu/ml) (B). 5'PPP-RNA also reduced replication of A/Mexico/ 4482/09 virus in Balb/c mice. 8 week old female Balb/c mice received $100 \mu \mathrm{g}$ of 5'PPP-RNA or PBS alone intravenously for 4 days and the animals were infected with 1000 MID $_{50}$ of 2009 pandemic virus (A/Mexi$\mathrm{co} / 4482 / 09)$ on day 1 . The lungs were collected on day 4 to determine viral titers ${ }^{*} P<0.05(n=5)$.
On day 4 post-challenge, lungs from all animals were collected to determine viral titers. Control group had significantly higher viral load in lungs when compared to those that received 5'PPP-RNA (Figure 2B). The viral titers from the 5'PPP-RNA group ranged from 40 through $10^{6}$ $\mathrm{pfu} / \mathrm{ml}$. Two animals showed viral titers of 40 and 50 and others showed $3 \times 10^{5}$ to $1 \times 10^{6} \mathrm{pfu} / \mathrm{ml}$. These data suggest that 5'PPP-RNA treatment inhibited viral replication.

\section{5'PPP-RNA induced upregulation of IFN $\beta$ and RIG-I}

Antiviral effect in response to 5'PPP-RNA has been shown to be associated with induced RIG-I expression and subsequent type I interferon production. Therefore, we investigated the ability of in vitro transcribed 5'PPPRNA to induce IFN $\beta$ and RIG-I in A549 cells in our experimental model by real-time RT-PCR. As shown in Figure 3A(i\&ii), transfection of A549 cells with 5'PPPRNA resulted in an approximately 200 -fold increase in IFN $\beta$ mRNA and $~ 80$-fold increase in RIG-I mRNA expression level in $24 \mathrm{hr}$. No induction was observed for RIG-I or IFN $\beta$ level in mock-transfected or A549 cells transfected with CIAP-RNA or with -OH-RNA. Timekinetics studies of RIG-I protein expression as shown in Figure 3B(i) suggest that 5'PPP-RNA mediated RIG-I induction was detectable by $6 \mathrm{hr}$, peaked at $8 \mathrm{hr}$, and was present even after $48 \mathrm{hr}$ although we observed a decline after $72 \mathrm{hr}$ of treatment (data not shown). Similar kinetics were observed for IFN $\beta$ expression by real-time RT-PCR (data not shown). Figure $3 \mathrm{~B}$ (ii) demonstrates the specific effect of 5'PPP-RNA on RIG-I expression at the protein level in A549 cells that is consistent with real time RTPCR data [Figure 3A(ii)]. A similar pattern of RIG-I induction by 5'PPP-RNA was observed in NHBE cells (data not shown). We also investigated 5'PPP-RNA induced RIG-I expression in A549 cells by immunostaining [Figure 3B(iii)]. A549 cells treated with 5'PPP-RNA showed increased cytosolic expression of RIG-I. Mock or CIAP-RNA transfected cells did not show detectable levels RIG-I. These experiments were also carried out in NHBE cells and similar effects of 5'PPP-RNA was observed (data not shown).

Activation of the innate immune system is critical for the induction and maintenance of host antiviral defenses. However, viruses also have evolved mechanism(s) that circumvent host immune responses. Several studies, including our own have shown independently that nonstructural protein (NS1) of influenza A viruses inhibits RIG-I function. We, therefore, investigated the expression of IFN $\beta$ and RIG-I as well as NS1 by real-time RTPCR in 5'PPP-RNA or CIAP-RNA transfected A549 cells that were either uninfected or infected with $\mathrm{H} 5 \mathrm{~N} 1$ virus at an MOI of 0.1 for $24 \mathrm{hr}$ following transfection. As shown in Figure 3C(i\&ii), 5'PPP-RNA induced IFN $\beta$ and 
(A)

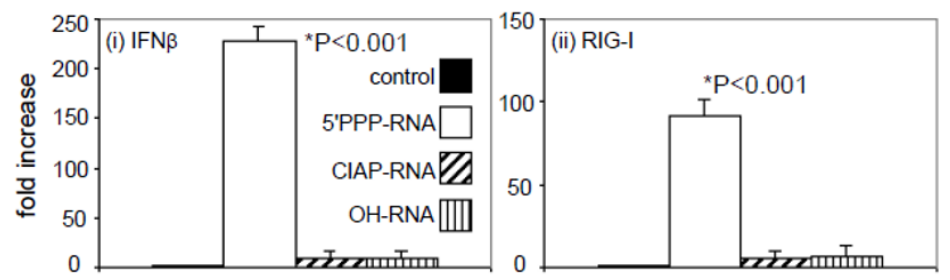

(B)

(i)

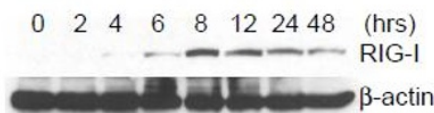

(ii)

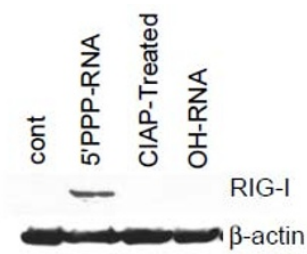

(C)

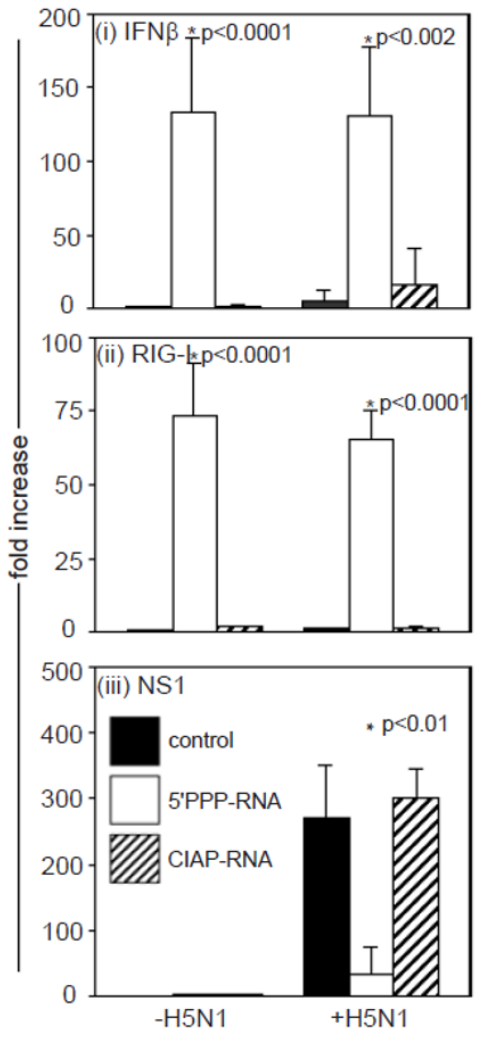

Figure 3 5'PPP-RNA induced RIG-I and IFN $\beta$ expression in A549 cells. (A) A549 $\left(1 \times 10^{6}\right.$ cells/well) in a 6-well tissue culture plate were mock-transfected (control) or transfected with $2 \mu \mathrm{g}$ of 5'PPP-RNA, CIAP-RNA or chemically synthesized OH-RNA using lipofectamine 2000 . After $24 \mathrm{hr}$ of treatment, (i) IFN $\beta$ and (ii) RIG-I mRNA expression was analyzed by real-time RT-PCR. All data were normalized to $\beta$-actin, a house keeping gene and expressed as fold increase. Data shown represent the mean \pm SD of three independent experiments. (B), (i) A549 cells were transfected with $2 \mu \mathrm{g}$ of $5^{\prime} P P P-R N A$ for the indicated times, and RIG-I expression was analyzed by immunoblot. (ii) A549 cells were mock-transfected or transfected with $2 \mu \mathrm{g}$ of 5'PPP-RNA, CIAP-RNA or chemically synthesized OH-RNA for 24 hr. RIG-l expression was analyzed by immunoblot. (iii) A549 cells grown on cover-slips were mocktransfected or transfected with $2 \mu \mathrm{g}$ of 5'PPP-RNA or CIAP-RNA for $24 \mathrm{hr}$. Cells were then paraformaldehyde fixed and immunostained with anti-RIG-I antibodies. Alexa fluor 594 goat anti-rabbit lgG Antibody (red fluorescence) or Alexa 488 (green fluorescence) were used as secondary antibodies. Nuclei were stained with Hoechst (blue fluorescence). (C) RNA was isolated from A549 cells mock transfected or trasfected with 5'PPP-RNA or CIAP-RNA for $24 \mathrm{hr}$ and then infected with wild-type H5N1 virus for $24 \mathrm{hr}$ (as described in Figure legend 1). Real-time RT-PCR was performed to analyze the expression of (i) IFN $\beta$, (ii) RIG-I and (iii) NS1. All data were normalized to $\beta$-actin, a house keeping gene and expressed as fold increase. Data shown represent the mean \pm SD of three independent experiments.

RIG-I induction remained unchanged in H5N1 infected A549 cells. H5N1 virus infection induced the expression of NS1 by 250-300-fold over uninfected A549 cells [Figure 3(iii)] and did not induce IFN $\beta$ and RIG-I and prior treatment with 5'PPP-RNA significantly inhibited viral NS1 expression. Similar effects were observed for 1918 infection in A549 cells (data not shown).

\section{Involvement of RIG-I and type 1 interferon in 5'PPP-RNA induced antiviral effect}

RIG-I activation has been reported to stimulate type 1 interferon expression that induces an antiviral state. To study the direct role of 5'PPP-RNA induced RIG-I and type 1 interferon induction we knockdown RIG-I or IFN $\alpha \beta$-receptor using gene specific siRNA. As shown in
Figure 4A, selective knockdown of RIG-I in A549 cells failed to induce antiviral effects when treated with 5'PPPRNA and infected with A/New York/02/2001. This confirms that 5'PPP-RNA mediated antiviral effects require RIG-I. 5'PPP-RNA treatment also resulted in induced IFN $\beta$ expression. To understand the correlation between increased IFN $\beta$ level and antiviral effect, we knocked down IFN- $\alpha / \beta$-receptors in A549 cells using siRNA, and treated the cells with 5'PPP-RNA followed by infection with A/New York/02/2001. As shown in Figure 4A, knocking down IFN $\alpha / \beta$-receptors significantly abrogated the antiviral effect of 5'PPP-RNA as compared to control siRNA knockdown. Furthermore, 5'PPP-RNA treatment of A549 cells with IFN- $\alpha / \beta$-receptors knockdown failed to induce the expression of RIG-I and IFN $\beta$ as assessed by 
(A)

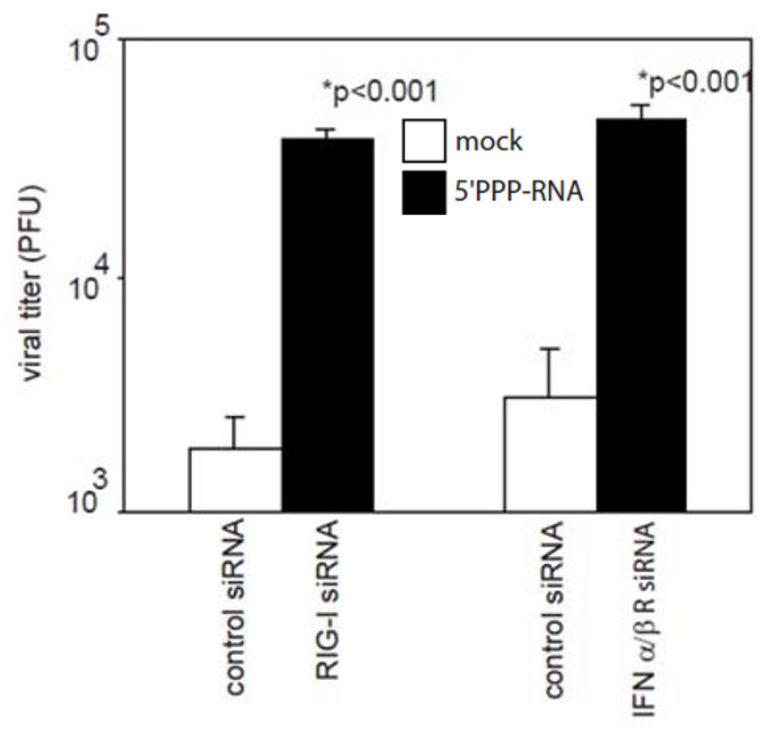

(B)

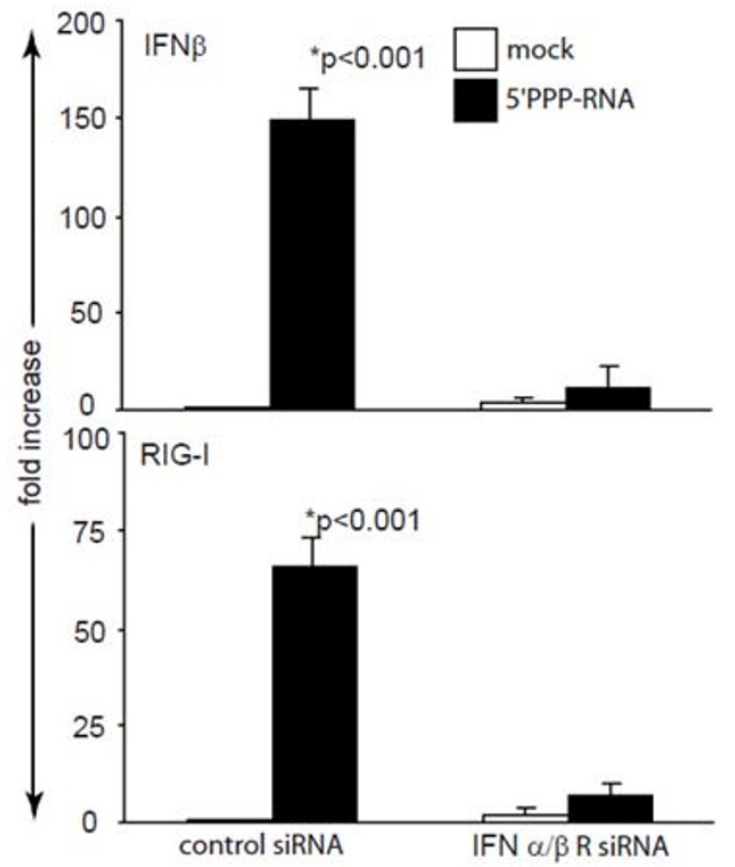

Figure 4 Indispensible role of type I interferon in RIG-I-dependent 5'PPP-RNA-induced antiviral effects. (A). A549 cells (1 × 106/well) in a 6-well plate were transfected with control siRNA or siRNA against RIG-I or IFN a $\beta$ receptors using DharmaFect 1 transfection reagent as per manufacturer instructions (Dharmacon, Lafayette, CO, USA). After $24 \mathrm{hr}$, cells were transfected with $2 \mu \mathrm{g}$ of 5'PPP-RNA. A549 cells were then infected with A/New York/02/2001, a H1N1 virus at $0.1 \mathrm{MOI}$. Supernatants collected after $24 \mathrm{hr}$ were analyzed for virus growth by plaque assay using MDCK cells. (B) A549 cells from experiment (A) were also analyzed for IFN $\beta$ and RIG-I expression by quantitative RT-PCR as described elsewhere. Data shown represent the mean \pm SD of three independent experiments.

quantitative RT-PCR (Figure 4B). We also measured IFN $\beta$, RIG-I and NS1 expression by qRTPCR and western blot analyses for all the viruses used in our studies. H5N1 and H1N1 viruses behaved the same way RIG-I or $\alpha \beta$ IFN-receptor gene knock-down experiments (data not shown) as A/New York/02/2001 virus. These data clearly indicate that type 1 interferon is not only required for antiviral effect but also for upregulating RIG-I expression by autocrine and paracrine manner.

\section{In vitro therapeutic potential of 5'PPP-RNA}

We also investigated the therapeutic potential of 5'PPPRNA in A549 cells infected with seasonal influenza virus A/New York/02/2001 and its oseltamivir-resistant H274Y mutant. As shown in Figure 5, A549 cells were first infected with/New York/02/2001 (i) or its oseltamivirresistant counterpart H274Y (ii). 5'PPP-RNA trasfection was carried out post $0 \mathrm{hr}, 4 \mathrm{hr}$ and $8 \mathrm{hr}$ infection. Data suggest that 5'PPP-RNA treatment inhibited both wildtype and drug-resistant virus replication when delivered up to $4 \mathrm{hr}$ post infection $(\mathrm{p}<0.05)$, whereas a weaker inhibitory effect was observed after $8 \mathrm{hr}$ post-infection.
We also investigated the IFN $\beta$ and RIG-I expression in these experiments. As shown in Figure 5(iii\&vi), 5'PPPRNA transfection post $8 \mathrm{hr}$ A/New York/02/2001 infection induced significantly low level of IFN $\beta$ (iii) and RIG-I (iv) as compared to those of $0 \mathrm{hr}$ or $4 \mathrm{hr}$ transfection. Similar results were observed for oseltamivir-resistant H274Y mutant (data not shown). A time-kinetics studies of NS1 expression following virus infection suggest that expression of NS1 reaches optimal by $8 \mathrm{hr}$ of infection (data not shown). This correlates with diminished antiviral effect of 5'PPP-RNA and down-regulation of type I interferon and RIG-I level at $8 \mathrm{hr}$ of infection suggesting NS1 interferes with RIG-I activation.

\section{Discussion}

Three influenza pandemics occurred during the 20th century, with varying degrees of severity; outcomes ranged from the high levels of illness and death observed during the 1918 Spanish flu pandemic (estimates of deaths range from 20 to 100 million) to the much lower levels observed during the pandemics of 1957 and 1968 


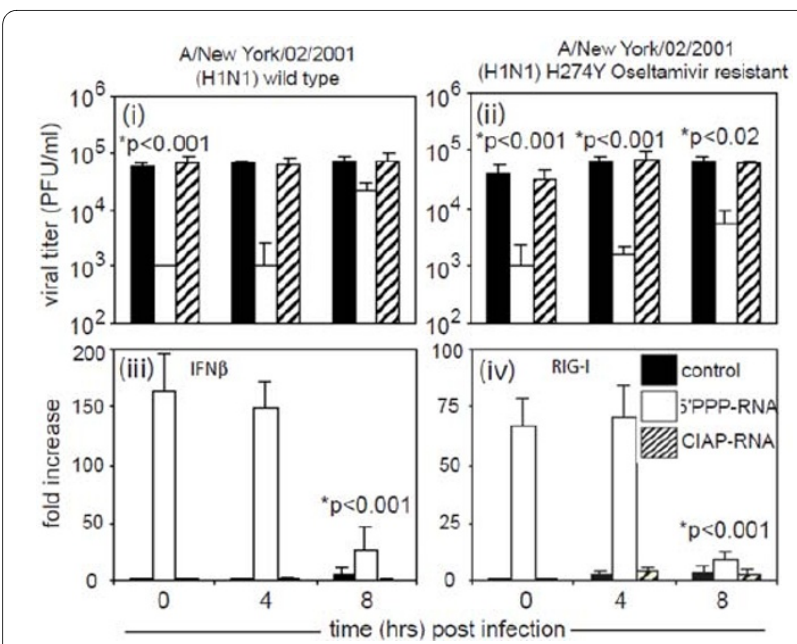

Figure 5 Therapeutic potential of 5'PPP-RNA. A459 cells $\left(1 \times 10^{6}\right.$ cells/well) in a 6-well tissue culture plate were infected with (i) wildtype A/New York/02/2001 and its (ii) H274Y oseltamivir-resistant A/ New York/02/2001 variant for the 0 hr, 4 hr or $8 \mathrm{hr}$ before treatment with 5'PPP-RNA or CIAP-RNA. Supernatants collected after $24 \mathrm{hr}$ of infection were assayed for viral titers as indicated in material and methods. Cells were harvested to assay IFN $\beta$ (iii) and RIG-I (iv) mRNA level by Real time RT-PCR. Results shown are mean \pm SD from three independent experiments and are expressed as viral titer (pfu/ml) or fold increase over controls.

(approximately one million deaths each) [54,55]. Furthermore, the spread of highly pathogenic avian influenza viruses since 2004 has also intensified concern over the emergence of novel strains of influenza with pandemic potential as exemplified by the current pandemic caused by a triple reassortant virus [9]. Since the vaccine was not available for use in the first wave of a pandemic, Oseltamivir, a neuraminidase inhibitor became the first choice for prophylactic and therapeutic intervention. The ongoing emergence of seasonal avian $\mathrm{H} 5 \mathrm{~N} 1$ as well as novel H1N1 pandemic influenza viruses that are resistant to one or other class of antiviral drugs underscores the fragility of the public health strategy to control seasonal influenza infections $[28,56,57]$. To overcome these challenges and improve preparedness against infections with oseltamivir-resistant viruses, developing novel antiviral prophylactic as well as therapeutic approaches that offer a broad spectrum approach and are independent of the genetic makeup of influenza viruses is absolutely critical.

In the present study, we explored the role of in vitro transcribed 5'PPP-RNA, a ligand for cytoplasmic RNA sensor, RIG-I, in antiviral innate immune response against a panel of influenza viruses including drug-resistant, potential pandemic as well as pandemic strains in human lung epithelial cells. The broad-spectrum prophylactic potential of 5'PPP-RNA against influenza viruses is clearly evident from our studies. 5'PPP-RNA significantly inhibited in vitro growth of not only wild-type drug-sen- sitive and resistant $\mathrm{H} 5 \mathrm{~N} 1$ strains with comparable efficacy but also highly pathogenic 1918 pandemic strain. We also included 2009 pandemic H1N1 viruses in our studies to see the effect of 5'PPP-RNA both in vitro and in vivo. Data shown Figure 2A clearly indicate that in vitro suppression level of A/California/08/09 was similar to that of other viruses used in this study. Furthermore, 5'PPP-RNA also inhibited A/California/08/09 viral replication in vivo in Balb/c mice. These data suggest that irrespective of type or subtypes, drug-susceptibility status, or in vivo virulence, the replication of influenza viruses was inhibited by 5'PPP-RNA. The dose and frequency of administration of 5'PPP-RNA may influence the extent of inhibition of viral replication.

Treatment with 5'PPP-RNA not only induced the expression of IFN-I but also upregulated RIG-I expression. 5'PPP-RNA induced expression of IFN-I and RIG-I was not affected by subsequent infection with H5N1 (Figure 3C) or 1918 pandemic influenza viruses (data not shown). Induction of these molecular regulators of innate immune pathway may be involved in the sustained action of the 5'PPP-RNA-induced antiviral effect.

Viruses have acquired mechanism(s) to escape host immune surveillance by inhibiting IFN induction pathways. The NS1 protein of Influenza A virus inhibits host antiviral defenses by direct interaction with RIG-I [4144]. 5'PPP-RNA treated A549 cells infected with H5N1 virus showed significant reduction of NS1 mRNA expression as compared to controls, thereby limiting the ability of the virus to interfere with the host innate immune system. RIG-I-mediated antiviral effect by 5 'PPP-RNA lasted for $48 \mathrm{hr}$ which also correlates with sustained induction of IFN-I that lasted more than $48 \mathrm{hr}$ as revealed by timekinetics studies (data not shown). To test the role of RIGI, we knocked down RIG-I expression using siRNA, which abrogated 5'PPP-RNA ability to induce IFN $\beta$ and to inhibit virus replication. Since, there is a significant increase in IFN $\beta$ in addition to RIG-I in 5'PPP-RNA treated lung epithelial cells, we investigated whether this effect is due to the action of IFN-I induced by initial interaction of 5'PPP-RNA with RIG-I. We abrogated the expression of IFN $\alpha / \beta$-receptors of A549 cells using siRNA and infected them subsequently with $\mathrm{A} / \mathrm{New}$ York/02/2001 virus. By knocking down the expression of IFN $\alpha / \beta$ receptors, we were unable to detect significant level of IFN $\beta$ and RIG-I induction following 5'PPP-RNA treatment and inhibitory effect on virus growth (Figure 4A\&4B). These findings suggest the direct involvement of RIG-I-induced type I IFN in the 5'PPP-RNA mediated antiviral effect. Our data support the previous findings that IFN can act in an autocrine or paracrine manner to induce its own expression as well as other antiviral modulators to generate an antiviral state [58]. Though type I interferon seems to be key player in antiviral action, sys- 
temic or local delivery of IFN $\beta$ may be toxic and may result in uncontrolled inflammation [59]. Activation induced type I interferon is self-regulated by feedback mechanisms and prevents side effects.

To evaluate the therapeutic potential of 5'PPP-RNA, we treated pre-infected (with wild-type and drug-resistant A/New York/02/2001) A549 cells with 5'PPP-RNA at different time-points. We observed relatively weak antiviral effect of 5'PPP-RNA, when A549 cells were transfected with 5'PPP-RNA post $8 \mathrm{hr}$ infection. Interestingly, at this time point we also observed significantly low RIG-I and IFN $\beta$ expression (Figure 5). These data again suggest the critical role of RIG-I and type I IFN expression which may have been suppressed due to NS1 expression at $8 \mathrm{hr}$ post-infection.

\section{Conclusions}

The findings described herein demonstrate that understanding host innate immune functions at the molecular level is a most promising strategy to identify targets, such as RIG-I for developing newer classes of drugs. These novel approaches that boost host antiviral innate immune defenses are broad spectrum in nature, rather than virusspecific as they inhibited replication of wild-type and drug-resistant strains of seasonal and avian viruses as well as pandemic influenza viruses. Since these approaches are based on stimulating host antiviral defenses, the possibility of viruses developing resistance to this approach is remote as these defenses are evolutionarily conserved.

\section{Methods}

\section{In vitro synthesis of 5'PPP-RNA}

5'PPP-RNAs were synthesized using T7 RNA polymerase. Using annealed complimentary oligo nucleotides, a DNA template was constructed that contains a T7 RNA polymerase promoter followed by the sequence of interest (AGCUUAACCUGUCCUUCAA) to be transcribed $[60,61]$. Twenty pmol of the DNA template were incubated with $25 \mathrm{U}$ T7 RNA polymerase, 40U RNase inhibitor in a buffer containing $40 \mathrm{mM}$ Tris- $\mathrm{Hcl}$ ( $\mathrm{pH}$ 8.0), $10 \mathrm{mM}$ DTT, $2 \mathrm{mM}$ spermidine- $\mathrm{HCl}, 20 \mathrm{mM} \mathrm{MgCl}_{2}$ and NTPs. DNA template was digested with DNase I and RNA was purified using phenol:chloroform extraction and ethanol precipitation. Size, integrity and single strandness of RNA was analyzed by RNase A digestion followed by gel electrophoresis. Calf intestine alkaline phosphatase (CIAP) treatment was performed to remove tri-phosphate groups from in vitro synthesized RNA. Briefly, $100 \mu \mathrm{g}$ of in vitro transcribed RNA was treated with $150 \mathrm{U}$ of CIAP for $3 \mathrm{hr}$ at $37^{\circ} \mathrm{C}$ in a buffer containing $50 \mathrm{mM}$ Tris- $\mathrm{HCl}$ (pH 8.0), $0.1 \mathrm{mM}$ EDTA and 50U of RNase inhibitor. RNA was purified as described above. Chemically synthesized RNA with same sequence and length that contains an $\mathrm{OH}$-group at its 5 -end was purchased from Dharmacon (Lafayette, CO, USA).

T7 polymerase driven in vitro transcribed 5'-PPP-RNA has been shown to contain dsRNA as well that activates RIG-I $[46,48]$. To investigate if our in vitro transcribe 5'PPP-RNA is single stranded RNA (ssRNA) and/or double stranded RNA,(dsRNA) we used RNase A treatment under the conditions that degrades ssRNA, but not dsRNA. This confirmed that in vitro transcribed RNA used in our study was RNA only (Additional file 3, Figure S3).

\section{Cell lines}

A549 cells were grown in DMEM (Life Technologies, Grand Island, NY) supplemented with $10 \%$ fetal bovine serum (FBS), 100? U/ml penicillin and $100 \mu \mathrm{g} / \mathrm{ml}$ streptomycin. Normal human bronchial epithelial (NHBE) cells (Base, Lonza, Switzerland) were maintained under the conditions and media specified by the supplier.

\section{Influenza viruses}

Seasonal viruses used in this study include the laboratory H1N1 strain A/Puerto Rico/8/34, wild-type H1N1 (A/ Texas/36/91 and its oseltamivir-resistant variant H274Y; wild-type A/New York/02/2001 and its H274Y oseltamivir-resistant variant), H3N2 (adamantane-resistant $\mathrm{A} /$ Wisconsin/06/94, A30V and A/Wisconsin/12/90, L26F), and $B$ viruses (wild-type B/Memphis/20/96 and its R152K mutant resistant to NA inhibitors zanamivir and oseltamivir), HPAI H5N1 viruses (zanamivir- and oseltamivir-sensitive and adamantane-resistant A/Vietnam/ $1203 / 2004$ and, adamantane- and oseltamivir-resistant virus variants A/Vietnam/30408/2005 (H274Y), and A/ Vietnam/HN30408/2005 (N294S),, 2009 pandemic H1N1 viruses, A/California/08/09 and A/Mexico/4482/09, and the reconstructed 1918 Spanish influenza pandemic virus (H1N1) generated by plasmid-based reverse genetics [62]. All human and avian wild-type and drug-resistant viruses were obtained from the influenza division $C D C$ repository.

\section{5'PPP-RNA treatment and influenza viral infections}

Cells were transfected with $2 \mu \mathrm{g}$ of in vitro transcribed 5'PPP-RNA, chemically synthesized RNA or CIAPtreated RNA using Lipofectamine 2000. This dose was determined by dose-kinetics studies using 1, 2, 4 and $6 \mu \mathrm{g}$ of RNA. After $24 \mathrm{hr}$, cells were infected with the different viruses used in this study in a 6-well plate. Unless specified, infection of cells was performed at a multiplicity of infection (MOI) of 0.1 with or without trypsin supplement. Each treatment was carried out in duplicate cultures. After $24 \mathrm{hr}$, cells were harvested for RNA and protein analysis and cell-culture supernatants were collected and stored at $-80^{\circ} \mathrm{C}$ for determination of viral titer by plaque assay as described previously using MDCK 
cells[41]. This time-point was determined by kinetics studies using PR8. To study the therapeutic potential of 5'PPP-RNA cells were infected with viruses first for 2,4 or $8 \mathrm{hr}$ followed by transfection with 5'PPP-RNA. Three independent experiments were performed at different times with each treatment carried out in duplicate cultures.

\section{Real Time RT-PCR}

Total RNA was isolated from cells using the RNAeasy kit (Qiagen, Valencia, CA, USA) and real time RT-PCR was conducted using a Stratagene Q3005 PCR machine for mRNA expression of RIG-I, IFN $\beta$, NS1, and $\beta$-actin. For each sample, $2 \mu \mathrm{g}$ of RNA was reverse transcribed using Superscript II Reverse Transcriptase (Invitrogen, Carlsbad, CA, USA) according to the manufacturer's directions. Parallel reactions without reverse transcriptase were included as negative controls. Reverse transcription reactions $\left(1 / 50^{\text {th }}\right.$ of each reaction) were analyzed in using syber green Q-PCR reagents (Stratagene, La Jolla, CA, USA). PCR condition was kept as $94^{\circ} \mathrm{C}$ for $15 \mathrm{~s}$, annealing at $56^{\circ} \mathrm{C}$ for $30 \mathrm{~s}$, and extension at $72^{\circ} \mathrm{C}$ for $30 \mathrm{~s}$ for a total of 45 cycles. The threshold cycle number for cDNA was normalized to that of $\beta$-actin mRNA, and the resulting value was converted to a linear scale. Data from three independent experiments were taken account for analysis. All data points fell into a normal distribution and there were no outliers.

Primer sets used for these studies are as follows:

IFN $\beta$ : forward 5'- TGG GAG GCT TGA ATA CTG CCT CAA - $3^{\prime}$

reverse 5'- TCT CAT AGA TGG TCA ATG CGG CGT $-3^{\prime}$

RIG-I: forward 5'- $A A A$ CCA GAG GCA GAG GAA GAG CAA - 3'

reverse 5'- TCG TCC CAT GTC TGA AGG CGT AAA $-3^{\prime}$

NS1: forward 5'-AGA AAG TGG CAG GCC CTC TTT GTA-3'

reverse 5'-TGT CCT GGA AGA GAA GGC AAT GGT $-3^{\prime}$

$\beta$-actin: forward 5'- ACC AAC TGG GAC GAC ATG GAG AAA - 3'

reverse 5'- TAG CAC AGC CTG GAT AGC AAC GTA $-3^{\prime}$

\section{Immunoblotting}

Cells were washed with chilled PBS and then lysed in 100 $\mu \mathrm{l}$ of ice-cold lysis buffer (50 mM Tris-Cl, $\mathrm{pH} 8.0,150$ $\mathrm{mM} \mathrm{NaCl}, 10 \% \mathrm{v} / \mathrm{v}$ glycerol, $1 \% \mathrm{v} / \mathrm{v}$ Triton X-100, $2 \mathrm{mM}$ EDTA, $1 \mathrm{mM}$ PMSF, $20 \mu \mathrm{M}$ leupeptin containing aprotinin $0.15 \mu \mathrm{g} / \mathrm{ml}$ ) for 20 minutes at $4^{\circ} \mathrm{C}$. The protein content of different samples was determined using a protein assay reagent (BioRad, Inc., CA, USA). Equal quantities of solubilized protein were resolved by $10 \%$ SDS-PAGE, blotted to nitrocellulose membrane and probed with the indicated primary antibodies. Anti-RIG-I was purchased from Axxora, LLC (San Diego, CA, USA). Anti- $\beta$-actin antibody was purchased from Sigma, St. Louis, MO, USA. Antibody signals were detected by chemiluminescence using secondary antibodies conjugated to horseradish peroxidase and an ECL detection kit (Amersham Biosciences, Inc., NJ, USA).

\section{Fluorescence microscopy}

A549 cells grown on cover-slips were mock-transfected or transfected with $2 \mu \mathrm{g}$ of 5'PPP-RNA or CIAP-RNA for $24 \mathrm{hr}$. Cell monolayers were then washed with cold PBS and fixed with $2 \%$ paraformaldehyde for $15 \mathrm{~min}$ at room temperature. Cells were permeablized with $0.05 \%$ saponin in PBS for $30 \mathrm{~min}$ at room temperature, and then blocked with blocking buffer (1\% BSA, 5\% normal goat serum and $0.05 \%$ saponin in $\mathrm{PBS}$ ) at room temperature. Cells were incubated with primary antibodies $(1 \mu \mathrm{g} / \mathrm{ml})$ at $4^{\circ} \mathrm{C}$ overnight, and were washed 3 times with wash buffer (0.05\% saponin in PBS). Cell monolayers were further incubated with secondary antibodies (Alexa 594 or 488) in blocking buffer for $1 \mathrm{hr}$ at room temperature followed by three washes with buffer. To stain nuclei, cells were incubated with Hoechst dye $(5 \mu \mathrm{M}$ in PBS containing $0.05 \%$ saponin). Cells were further washed (3 times) with PBS, and were mounted on slides using Prolong antifade mounting media (Invitrogen, Carlsbad, CA, USA) and were observed under a Zeiss LSM 510 fluorescence microscope.

\section{In vivo studies}

Female Balb/c mice 6-12 weeks old purchased from Jackson Laboratories were intravenously injected $100 \mu \mathrm{g}$ of 5'PPP-RNA, capped 5'-RNA or PBS complexed with in vivo-jetPEI according to manufacturer's protocol (Polyplus-transfection Inc, San Diego, CA USA) in a volume of $200 \mu \mathrm{l}$ for 4 days. On day 1 , mice were challenged intranasaly with $1000 \mathrm{MID}_{50}$ of 2009 pandemic virus (A/Mexico/ 4482/09). A separate group of animals that received only 5'PPP-RNA complexed with in vivo-jetPEI without viral challenge were observed to determine changes in body weight and activity. Lungs from control and treated challenged animals were collected on day 4 to determine viral titers using MDCK cells as described earlier.

\section{Statistical Methods}

To determine the statistical significance among the 5'PPP-RNA or CIAP-RNA treated and untreated groups, we used Analysis of variance and a value of $P<0.05$ was considered significant. All data points were included in the analysis and there were no outliers. 


\section{Additional material}

Additional file 1 Figure S1. 5'PPP-RNA inhibits replication of drug-resistant human viruses. A459 cells $\left(1 \times 10^{6}\right.$ cells/well) in a 6 -well tissue culture plate were mock-transfected or transfected with $2 \mu \mathrm{g}$ of 5'PPP-RNA or CIAPRNA for $24 \mathrm{hr}$ and then infected with (a\&b) wild-type and drug-resistant human $\mathrm{H} 1 \mathrm{~N} 1$ viruses; (b\&c) drug-resistant H3N2 viruses and (d\&e) wild-type and drug-resistant B viruses. Supernatants collected were assayed for viral titers as indicated in material and methods. Results shown are mean \pm SD from three independent experiments and are expressed as viral titer (pfu/ $\mathrm{ml})$.

Additional file 2 Figure S2. Testing viral colonies if they are interferon escape mutant. A/NewYork/02/2001 colonies from 5'PPP-RNA treated A549 cells grown on MDCK cell were isolated and viral stocks were made by growing them in MDCK cells. Subsequently, these viruses were tested for 5'PPP-RNA sensitivity in A549 cells transfected $24 \mathrm{hr}$ earlier with either CIAPRNA or 5'PPP-RNA. Culture supernatants were collected $24 \mathrm{hr}$ post-infection to determine viral titers in MDCK cells as described in materials and methods.

\section{Additional file 3 Figure S3. Analysis of size, integrity and single or} double-strandness of RNA. In vitro transcribed RNA (1 $\mu \mathrm{g})$ generated by T7 polymerase was digested with $0.1 \mu \mathrm{g} / \mathrm{ml}$ RNase A (Ambion) or DNase I $(10 \mathrm{U} / \mathrm{ml})$ (Ambion) at 37C for $1 \mathrm{hr}$, separated on agarose gel, and visualized by ethidium bromide staining.

\section{Competing interests}

The authors declare that they have no competing interests.

\section{Authors' contributions}

PR participated in the planning and execution of the experiments, analyses of the results, and manuscript writing. $\amalg, V D$, and MAH performed studies with human and avian viruses. VJ, WGD, JBB, MEW and MBP assisted in making 5'PPP-RNA and tested mRNA samples for the expression of various host innate immune response genes with cytokine arrays. SG provided assistance in assessing the functionality of cytokines and chemokines. $\mathrm{HZ}$ and TMT performed studies with the 1918 pandemic virus. LG, JMK, AG, and TF provided advice in the planning and execution of the studies. SS participated in the planning, coordination, supervision, and execution of the experiments that led to the present manuscript. All the authors saw and approved the final version of the manuscript.

\section{Acknowledgements}

We thank Alexander Klimov and Nancy Cox for their advice and critical reading of this manuscript. These studies are funded by a grant awarded to SS by National Vaccine Program Office, and by NIAID grants RO1 Al46954, U19 Al62623, P01 Al058113, U19 Al83025, and CRIP (Center for Research on Influenza Pathogenesis, NIAID contract number HHSN266200700010C to AG-S. The findings and conclusions in this report are those of the authors and do not necessarily represent the views of the funding agency or Centers for Disease Control and Prevention.

\section{Author Details}

1 Influenza Division, NCIRD, Centers for Disease Control and Prevention, 1600 Clifton Road, Atlanta, GA 30333, USA, 2Mount Sinai School of Medicine, One Gustave L Levy Place, New York, NY 10029, USA and 'Laboratory of Molecular Genetics, Institute for Virus Research, Kyoto University, Kyoto, Japan

Received: 25 March 2010 Accepted: 21 May 2010

Published: 21 May 2010

\section{References}

1. Thompson WW, Shay DK, Weintraub E, Brammer L, Cox N, Anderson LJ, Fukuda K: Mortality associated with influenza and respiratory syncytial virus in the United States. JAMA 2003, 289:179-86.

2. Zambon MC: Epidemiology and pathogenesis of influenza. $J$ Antimicrob Chemother 1999, 44(Suppl B):3-9.

3. Zambon MC: The pathogenesis of influenza in humans. Rev Med Virol 2001, 11:227-41.

4. Nicholson KG, McNally T, Silverman M, Simons P, Zambon MC: Influenzarelated hospitalizations among young children in Leicestershire. Pediatr Infect Dis J 2003, 22:S228-30.
5. OIE: Update on avian influenza in animals (type H5). 2008 [http:// www.oie.int/downld/AVIAN\%20INFLUENZA/A Al-Asia.htm]. Accessed on 02/29/2008.

6. WHO: Cumulative Number of Confirmed Human Cases of Avian Influenza A/(H5N1) Reported to WHO. 2010 [http://www.who.int/csr/ disease/avian influenza/country/cases table 201005 06/en/ index.html]. accessed on 05/12/2010

7. Fauci AS: Pandemic influenza threat and preparedness. Emerg Infect Dis 2006, 12:73-7.

8. Poland GA: Vaccines against avian influenza--a race against time. $\mathrm{N}$ Engl J Med 2006, 354:1411-3.

9. Dawood FS, Jain S, Finelli L, Shaw MW, Lindstrom S, Garten RJ, Gubareva LV, Xu X, Bridges CB, Uyeki TM: Emergence of a novel swine-origin influenza A (H1N1) virus in humans. N Engl J Med 2009, 360:2605-15.

10. Hancock K, Veguilla V, Lu X, Zhong W, Butler EN, Sun H, Liu F, Dong L, DeVos JR, Gargiullo PM, Brammer TL, Cox NJ, Tumpey TM, Katz JM: Crossreactive antibody responses to the 2009 pandemic $\mathrm{H} 1 \mathrm{~N} 1$ influenza virus. N Engl J Med 2009, 361:1945-52.

11. WHO: World now at the start of 2009 influenza pandemic. 2009 [http:// www.who.int/mediacentre/news/statements/2009/ h1n1 pandemic phase6 20090611/en/index.html]. Accessed on September 8, 2009.

12. Bridges CB, Thompson WW, Meltzer MI, Reeve GR, Talamonti WJ, Cox NJ, Lilac HA, Hall H, Klimov A, Fukuda K: Effectiveness and cost-benefit of influenza vaccination of healthy working adults: A randomized controlled trial. JAMA 2000, 284:1655-63.

13. Fiore AE, Shay DK, Broder K, Iskander JK, Uyeki TM, Mootrey G, Bresee JS, Cox NS: Prevention and control of influenza: recommendations of the Advisory Committee on Immunization Practices (ACIP), 2008. MMWR Recomm Rep 2008, 57:1-60.

14. Demicheli V, Rivetti D, Deeks JJ, Jefferson TO: Vaccines for preventing influenza in healthy adults. Cochrane Database Syst Rev 2004:CD001269.

15. Rivetti D, Jefferson T, Thomas R, Rudin M, Rivetti A, Di Pietrantonj C, Demicheli V: Vaccines for preventing influenza in the elderly. Cochrane Database Syst Rev 2006, 3:CD004876.

16. CDC: 2009 H1N1 Flu ("Swine Flu") and You. 2009 [http://www.cdc.gov/ H1N1flu/qa.htm]. Accessed on November 4, 2009.

17. Hayden FG, Pavia AT: Antiviral management of seasonal and pandemic influenza. J Infect Dis 2006, 194(Suppl 2):S119-26.

18. Moscona A: Oseltamivir resistance--disabling our influenza defenses. $N$ Engl J Med 2005, 353:2633-6.

19. Schunemann HJ, Hill SR, Kakad M, Bellamy R, Uyeki TM, Hayden FG, Yazdanpanah Y, Beigel J, Chotpitayasunondh T, Del MC, Farrar J, Tran TH, Ozbay B, Sugaya N, Fukuda K, Shindo N, Stockman L, Vist GE, Croisier A, Nagjdaliyev A, Roth C, Thomson G, Zucker H, Oxman AD: WHO Rapid Advice Guidelines for pharmacological management of sporadic human infection with avian influenza A (H5N1) virus. Lancet Infect Dis 2007, 7:21-31

20. Moscona A: Neuraminidase inhibitors for influenza. N Engl J Med 2005, 353:1363-73.

21. Deyde VM, Xu X, Bright RA, Shaw M, Smith CB, Zhang Y, Shu Y, Gubareva LV, Cox NJ, Klimov Al: Surveillance of resistance to adamantanes among influenza $\mathrm{A}(\mathrm{H} 3 \mathrm{~N} 2)$ and $\mathrm{A}(\mathrm{H} 1 \mathrm{~N} 1)$ viruses isolated worldwide. J Infect Dis 2007, 196:249-57

22. Drinka PJ, Haupt T: Emergence of rimantadine-resistant virus within 6 days of starting rimantadine prophylaxis with oseltamivir treatment of symptomatic cases. J Am Geriatr Soc 2007, 55:923-6.

23. He G, Qiao J, Dong C, He C, Zhao L, Tian Y: Amantadine-resistance among H5N1 avian influenza viruses isolated in Northern China 191. Antiviral Res 2008, 77:72-6.

24. Shobugawa Y, Saito R, Sato I, Li D, Suzuki Y, Sasaki A, Sato M, Suzuki H: Recurrence and persistence of fever in children who developed amantadine-resistant influenza viruses after treatment. Tohoku J Exp Med 2008, 214:129-38.

25. CDC: Update: Influenza Activity United States. September 30, 2007-February 9, 2008 Early Release. MMWR Morb Mortal Wkly Rep 2008, 57:1-5.

26. ECDC: Resistance to oseltamivir (Tamiflu) found in some European influenza virus samples. Resistance to oseltamivir (Tamiflu) found in some European influenza virus samples 2008. Accessed on July 14, 2009.

27. WHO: Pandemic (H1N1) 2009 briefing note 1. Viruses resistant to oseltamivir (Tamiflu) identified. 2009 [http://www.who.int/csr/disease/ swineflu/notes/h1n1 antiviral resistance 20090708/en/index.html]. Accessed on september 8, 2009. 
28. de Jong MD, Tran TT, Truong HK, Vo MH, Smith GJ, Nguyen VC, Bach VC, Phan TQ, Do QH, Guan Y, Peiris JS, Tran TH, Farrar J: Oseltamivir resistance during treatment of influenza $\mathrm{A}$ (H5N1) infection. NEngl J Med 2005 353:2667-72.

29. Akira S: Innate immunity to pathogens: diversity in receptors for microbial recognition. Immunol Rev 2009, 227:5-8.

30. Sambhara S, Lehrer Rl: The innate immune system: a repository for future drugs? Expert Review of Anti-infective Therapy 2007, 5:1-5.

31. Ranjan P, Bowzard JB, Schwerzmann JW, Jeisy-Scott V, Fujita T, Sambhara $\mathrm{S}$ : Cytoplasmic nucleic acid sensors in antiviral immunity. Trends $\mathrm{Mol}$ Med 2009, 15:359-68.

32. Seth RB, Sun L, Chen ZJ: Antiviral innate immunity pathways. Cell Res 2006, 16:141-7.

33. Kang DC, Gopalkrishnan RV, Wu Q, Jankowsky E, Pyle AM, Fisher PB: MDA5: An interferon-inducible putative RNA helicase with double-stranded RNA-dependent ATPase activity and melanoma growth-suppressive properties. Proc Natl Acad Sci USA 2002, 99:637-42.

34. Yoneyama M, Kikuchi M, Natsukawa T, Shinobu N, Imaizumi T, Miyagishi M, Taira K, Akira S, Fujita T: The RNA helicase RIG-I has an essential function in double-stranded RNA-induced innate antiviral responses. Nat Immunol 2004, 5:730-7.

35. Takaoka A, Wang Z, Choi MK, Yanai H, Negishi H, Ban T, Lu Y, Miyagishi M, Kodama T, Honda K, Ohba Y, Taniguchi T: DAI (DLM-1/ZBP1) is a cytosolic DNA sensor and an activator of innate immune response. Nature 2007, 448:501-5.

36. Hornung V, Ablasser A, Charrel-Dennis M, Bauernfeind F, Horvath G, Caffrey DR, Latz E, Fitzgerald KA: AIM2 recognizes cytosolic dsDNA and forms a caspase-1-activating inflammasome with ASC. Nature 2009, 458:514-8.

37. Cardenas WB, Loo YM, Gale M Jr, Hartman AL, Kimberlin CR, MartinezSobrido L, Saphire EO, Basler CF: Ebola virus VP35 protein binds doublestranded RNA and inhibits alpha/beta interferon production induced by RIG-I signaling. J Virol 2006, 80:5168-78.

38. Kaukinen P, Sillanpaa M, Kotenko S, Lin R, Hiscott J, Melen K, Julkunen I: Hepatitis C virus NS2 and NS3/4A proteins are potent inhibitors of host cell cytokine/chemokine gene expression. Viro/ J 2006, 3:66.

39. Chen Z, Benureau Y, Rijnbrand R, Yi J, Wang T, Warter L, Lanford RE, Weinman SA, Lemon SM, Martin A, Li K: GB virus B disrupts RIG-I signaling by NS3/4A-mediated cleavage of the adaptor protein MAVS. J Virol 2007, 81:964-76.

40. Li WX, Li H, Lu R, Li F, Dus M, Atkinson P, Brydon EW, Johnson KL, GarciaSastre A, Ball LA, Palese P, Ding SW: Interferon antagonist proteins of influenza and vaccinia viruses are suppressors of RNA silencing. Proc Natl Acad Sci USA 2004, 101:1350-5.

41. Guo Z, Chen LM, Zeng H, Gomez JA, Plowden J, Fujita T, Katz JM, Donis RO, Sambhara S: NS1 protein of influenza A virus inhibits the function of intracytoplasmic pathogen sensor, RIG-I. Am J Respir Cell Mol Biol 2007 , 36:263-9.

42. Pichlmair A, Schulz O, Tan CP, Naslund TI, Liljestrom P, Weber F, Reis e S: RIG-I-mediated antiviral responses to single-stranded RNA bearing 5'phosphates. Science 2006, 314:997-1001.

43. Opitz B, Rejaibi A, Dauber B, Eckhard J, Vinzing M, Schmeck B, Hippenstiel $S$, Suttorp N, Wolff T: IFNbeta induction by influenza $A$ virus is mediated by RIG-I which is regulated by the viral NS1 protein. Cell Microbiol 2007, 9:930-8.

44. Mibayashi M, Martinez-Sobrido L, Loo YM, Cardenas WB, Gale M Jr, GarciaSastre A: Inhibition of retinoic acid-inducible gene I-mediated induction of beta interferon by the NS1 protein of influenza A virus. $J$ Virol 2007, 81:514-24.

45. Yoneyama M, Fujita T: RIG-I family RNA helicases: cytoplasmic sensor for antiviral innate immunity. Cytokine Growth Factor Rev 2007, 18:545-51.

46. Schmidt A, Schwerd T, Hamm W, Hellmuth JC, Cui S, Wenzel M, Hoffmann FS, Michallet MC, Besch R, Hopfner KP, Endres S, Rothenfusser S: 5'triphosphate RNA requires base-paired structures to activate antiviral signaling via RIG-I. Proc Natl Acad Sci USA 2009, 106:12067-72.

47. Hornung V, Ellegast J, Kim S, Brzozka K, Jung A, Kato H, Poeck H, Akira S, Conzelmann KK, Schlee M, Endres S, Hartmann G: 5'-Triphosphate RNA is the ligand for RIG-I. Science 2006, 314:994-7.

48. Schlee M, Roth A, Hornung V, Hagmann CA, Wimmenauer V, Barchet W, Coch C, Janke M, Mihailovic A, Wardle G, Juranek S, Kato H, Kawai T, Poeck H, Fitzgerald KA, Takeuchi O, Akira S, Tuschl T, Latz E, Ludwig J, Hartmann $\mathrm{G}$ : Recognition of 5 ' triphosphate by RIG-I helicase requires short blunt double-stranded RNA as contained in panhandle of negative-strand virus. Immunity 2009, 31:25-34.

49. Rehwinkel J, Tan CP, Goubau D, Schulz O, Pichlmair A, Bier K, Robb N, Vreede F, Barclay W, Fodor E, Reis e Sousa C: RIG-I detects viral genomic RNA during negative-strand RNA virus infection. Cell 2010, 140:397-408.

50. Saito T, Gale M Jr: Differential recognition of double-stranded RNA by RIG-I-like receptors in antiviral immunity. J Exp Med 2008, 205:1523-7.

51. Saito T, Owen DM, Jiang F, Marcotrigiano J, Gale M Jr: Innate immunity induced by composition-dependent RIG-I recognition of hepatitis C virus RNA. Nature 2008, 454:523-7.

52. Ablasser A, Poeck H, Anz D, Berger M, Schlee M, Kim S, Bourquin C, Goutagny N, Jiang Z, Fitzgerald KA, Rothenfusser S, Endres S, Hartmann G, Hornung V: Selection of molecular structure and delivery of RNA oligonucleotides to activate TLR7 versus TLR8 and to induce high amounts of IL-12p70 in primary human monocytes. J Immunol 2009, 182:6824-33.

53. Chiu YH, Macmillan JB, Chen ZJ: RNA polymerase III detects cytosolic DNA and induces type I interferons through the RIG-I pathway. Cell 2009, 138:576-91.

54. Johnson NP, Mueller J: Updating the accounts: global mortality of the 1918-1920 "Spanish" influenza pandemic. Bull Hist Med 2002, 76:105-15.

55. Taubenberger JK, Morens DM: 1918 Influenza: the mother of all pandemics. Emerg Infect Dis 2006, 12:15-22.

56. Cheung CL, Rayner JM, Smith GJ, Wang P, Naipospos TS, Zhang J, Yuen KY, Webster RG, Peiris JS, Guan Y, Chen H: Distribution of amantadineresistant H5N1 avian influenza variants in Asia. J Infect Dis 2006, 193:1626-9

57. Kiso M, Mitamura K, Sakai-Tagawa Y, Shiraishi K, Kawakami C, Kimura K, Hayden FG, Sugaya N, Kawaoka Y: Resistant influenza A viruses in children treated with oseltamivir: descriptive study. Lancet 2004, 364:759-65.

58. Haller O, Kochs G, Weber F: The interferon response circuit: induction and suppression by pathogenic viruses. Virology 2006, 344:1 19-30

59. Friedman RM: Clinical uses of interferons. Br J Clin Pharmacol 2008 , 65:158-62.

60. Hornung V, Guenthner-Biller M, Bourquin C, Ablasser A, Schlee M, Uematsu S, Noronha A, Manoharan M, Akira S, de Fougerolles A, Endres S, Hartmann G: Sequence-specific potent induction of IFN-alpha by short interfering RNA in plasmacytoid dendritic cells through TLR7. Nature Medicine 2005, 11:263-70.

61. Kim DH, Longo M, Han Y, Lundberg $\mathrm{P}$, Cantin E, Rossi JJ: Interferon induction by siRNAs and ssRNAs synthesized by phage polymerase. Nat Biotechnol 2004, 22:321-5.

62. Tumpey TM, Basler CF, Aguilar PV, Zeng H, Solçrzano A, Swayne DE, Cox NJ, Katz Jm, Taubenberger JK, Palese P, Garcia-Sastre A: Characterization of the reconstructed 1918 Spanish influenza pandemic virus. Science 2005, 310:77-80

doi: $10.1186 / 1743-422 X-7-102$

Cite this article as: Ranjan et al., 5'PPP-RNA induced RIG-I activation inhibits drug-resistant avian H5N1 as well as 1918 and 2009 pandemic influenza virus replication Virology Journal 2010, 7:102

\section{Submit your next manuscript to BioMed Centra and take full advantage of:}

- Convenient online submission

- Thorough peer review

- No space constraints or color figure charges

- Immediate publication on acceptance

- Inclusion in PubMed, CAS, Scopus and Google Scholar

- Research which is freely available for redistribution 